\title{
Euspermatozoa and paraspermatozoa of the relict cerithiacean gastropod, Campanile symbolicum (Prosobranchia, Mesogastropoda)
}

\author{
John. M. Healy* \\ Department of Zoology, University of Queensland; St. Lucia 4067, Brisbane, \\ Queensland, Australia
}

\begin{abstract}
Euspermatozoa and paraspermatozoa of Campanile symbolicum Iredale, 1917 - a large, relict cerithiacean from Western Australia - have been examined using transmission electron microscopy and phase-contrast light microscopy. The euspermatozoa resemble those of many other mesogastropods with the important exception that the midpiece region exhibits unusual and possibly unique features. These include possession of seven or eight straight, periaxonemal elements (each containing scattered cristae) and a closely associated sheath composed of electrondense segments which are semicylindrical in shape and longitudinally aligned. This sheath - here termed the 'accessory midpiece sheath'-surrounds only one half of the periaxonemal midpiece elements and lies outside the mitochondrial membrane (but nevertheless within the plasma membrane). Two types of paraspermatozoa occur in Campanile:(1) those with a nuclear core within the mosaic sheath of the head (nucleate paraspermatozoa) and (2) those lacking a nuclear core (dense blocks of mosaic sheath surrounding one to three axonemes - anucleate paraspermatozoa). An acrosome-like structure forms the apex of the head in both types of paraspermatozoa, while beyond the head region, electron-dense glycogen deposits are associated with each of the multiple tails. While the form of Campanile paraspermatozoa suggests links with families such as the Cerithiidae, Potamididae and Turritellidae, the highly unusual morphology of the euspermatozoan midpiece indicates that the Campanilidae should occupy an isolated position within the superfamily Cerithiacea.
\end{abstract}

\section{INTRODUCTION}

The superfamily Cerithiacea comprises a number of families of herbivorous or detritiphagous mesogastropods characterized in part by their turritelliform shells (littoriniform or disjunctly coiled in some), open genital ducts (both sexes, aphallic males) and also certain spermatozoal features. Major families such as the Cerithiidae and Potamididae are well represented in tropical waters, and to a lesser degree in temperate regions. By comparison, other families - for example Modulidae, Planaxidae, Siliquariidae - are more patchily distributed with fewer, though still very common tropical or subtropical species. Two cerithiacean families - the Campanilidae and Diastomatidae

\footnotetext{
- Present address: School of Biological Sciences (Zoology Building), University of Sydney; Sydney 2000, New South Wales, Australia
} 
- are each represented by a single living species inhabiting shallow water off the southwestern and southern coasts of Australia (Ludbrook, 1971; Houbrick, 1981a, b, 1984a, b). The fossil record indicates that the Campanilidae (shells large and heavy) and Diastomatidae (shells of moderate size with fine, cancellate sculpture) were reasonably speciose and wide ranging at least as late as the Miocene, but have since then, declined to their current 'relict' status (see discussions in Houbrick, 1981a, b). According to Houbrick (1981a, 1984a) the decline of the Campanilidae may have been due to major geographical changes (the Messinian crisis), increasing trophic competition from the herbivorous mesogastropod family Strombidae or perhaps a combination of these two factors. Shells of Campanile symbolicum and Diastoma melanioides (Reeve, 1849) do not differ substantially from those of extinct species (see Houbrick, 1981a, b) and presumably both of these gastropods are anatomically and spermatozoically 'typical' of their respective families. Clearly these surviving members of the Campanilidae and Diastomatidae are of systematic interest and each has been the subject of very detailed conchological and anatomical analysis by Houbrick (1981a, b, 1984a, b). Houbrick concluded that the Diastomatidae should be grouped close to the Cerithiidae, Potamididae and Melanopsidae, but expressed uncertainty as to the exact relationship of the Campanilidae with other cerithiacean families. Through the kindness of Dr. F. Wells (Western Australian Museum), the author has had the opportunity to examine the fine structure of spermatozoa of C. symbolicum and to compare these results with previous studies of cerithiacean spermatozoa (Healy \& Jamieson, 1981; Healy, 1982a, b, 1983a, 1984; Afzeluis \& Dallai, 1983; Melone et al., 1980; Giusti, 1971; Giusti \& Selmi, 1982a). This investigation forms the basis of the present paper.

\section{MATERIALS AND METHODS}

Live specimens of Campanile symbolicum (hereafter referred to simply as Campanile) were collected on three occasions (March, 1981; September, 1981; June, 1982) from a depth of two metres at Point Peron, Western Australia, and dispatched by air to the University of Queensland where the present work was carried out. Only a single specimen from those collected in June 1982 was found to contain spermatozoa within the sperm duct. It is most surprising that sperm were not found in specimens collected in September 1981 since spawning evidently occurs in this species from September to November (see Houbrick, 1981a), Following removal of the shell spire, a section of the sperm duct and portions of the gonad (which appeared poorly developed) were removed and fixed immediately in cold $3 \%$ glutaraldehyde (phosphate-buffered $0.1 \mathrm{M}$. pH 7.2, sucrose adjusted) for two $h$, then rinsed, osmicated, rinsed again and embedded in Spurr's medium (see schedule of Healy, 1983a), Ultrathin sections were cut using an LKB Ultrotome (IV); collected on copper grids (200 mesh), stained, and then viewed with Siemens Elmiskop I and AEI Corinth 500 transmission electron microscopes. Light microscopic observations were carried out using a Wild 12 microscope adjusted for phasecontrast microscopy. Voucher specimens of Campanile have been lodged with the Queensland Museum (Brisbane) (registration number - MO 15908). 


\section{RESULTS}

\section{Euspermatozoa}

The euspermatozoa of Campanile symbolicum, like those of most other internally fertilizing gastropods, possess an acrosome, nucleus, midpiece and glycogen piece. Each of these sperm features is described below with emphasis being placed on structures or configurations which distinguish Campanile euspermatozoa from those of other cerithiaceans and more generally those of other gastropods.

\section{Acrosome}

The acrosomal complex of Campanile is situated at the apex of the nucleus and is divisible into three principle components : (1) acrosomal cone, (2) axial rod material and (3) basal plate. Longitudinal sections show that the acrosomal cone is approximately 0.65 $\mu \mathrm{m}$ long and membrane-bound, with a basal invagination extending almost the full length of the cone (Figs 1A, B). The acrosomal cone is circular in transverse section (Fig. $1 \mathrm{~A}$ ) and on occasion, internal lamellate substructure is visible within the cone wall (Fig. $1 \mathrm{~B}$ - longitudinal section). Axial rod material, evidently organized as a hollow, electrondense cylinder (length $0.6 \mu \mathrm{m}$ ) lies within the cone invagination (Figs 1A,B). The basal plate is $0.04 \mu \mathrm{m}$ thick and is positioned between the nuclear apex and the basal rim of the acrosomal cone (Fig. 1B). A double membrane fixed to the periphery of the basal plate, surrounds the lower half of the acrosomal cone (Fig. 1B). Although a similar membrane occurs in euspermatozoa of some of mesogastropod groups, this is the first recorded incidence of this structure in any cerithiacean species.

\section{Nucleus}

The euspermatozoon nucleus is rod-shaped, approximately $9.5 \mu \mathrm{m}$ in length and enclosed by the plasma and nuclear membranes (Fig. 1C). A shallow basal invagination $(0.8 \mu \mathrm{m}$ in length) contains the proximal portion of the axoneme and the centriolar derivative' (a modification of the axonemal complex - doublets linked by a ring of granular material) (Figs 1D-G). The innermost reach of the invagination appears to be occupied by a granular matrix which completely obscures the axonemal microtubules (see Fig. 1F). No evidence of a classic 'triplet' centriole could be found.

\section{Midpiece}

The midpiece is composed of a $9+2$ axoneme surrounded sequentially by : (1) seven or eight straight midpiece elements (contained within the mitochondrial membrane), and (2) an accessory midpiece sheath (lying outside the mitochondrial membrane, but nevertheless within the plasma membrane) (Figs 1F,H-J). All seven to eight midpiece elements contain irregularly arranged cristae, in striking contrast to the parallel cristal plates observed in the four midpiece elements of other cerithiacean euspermatozoa. The flat surface of adjoining midpiece elements ensures that the elements collectively form a compact tube around the axoneme. The most distinctive feature of the midpiece - and one that may prove to be unique to Campanile - is the accessory midpiece sheath (Figs $1 \mathrm{~F}, \mathrm{H}-\mathrm{J}$ ). This sheath is closely applied to the mitochondrial membrane and is composed of very electron-dense segments, semicylindrical in shape and arranged end-to-end (Fig. 1F). Each segment of the sheath : (1) 

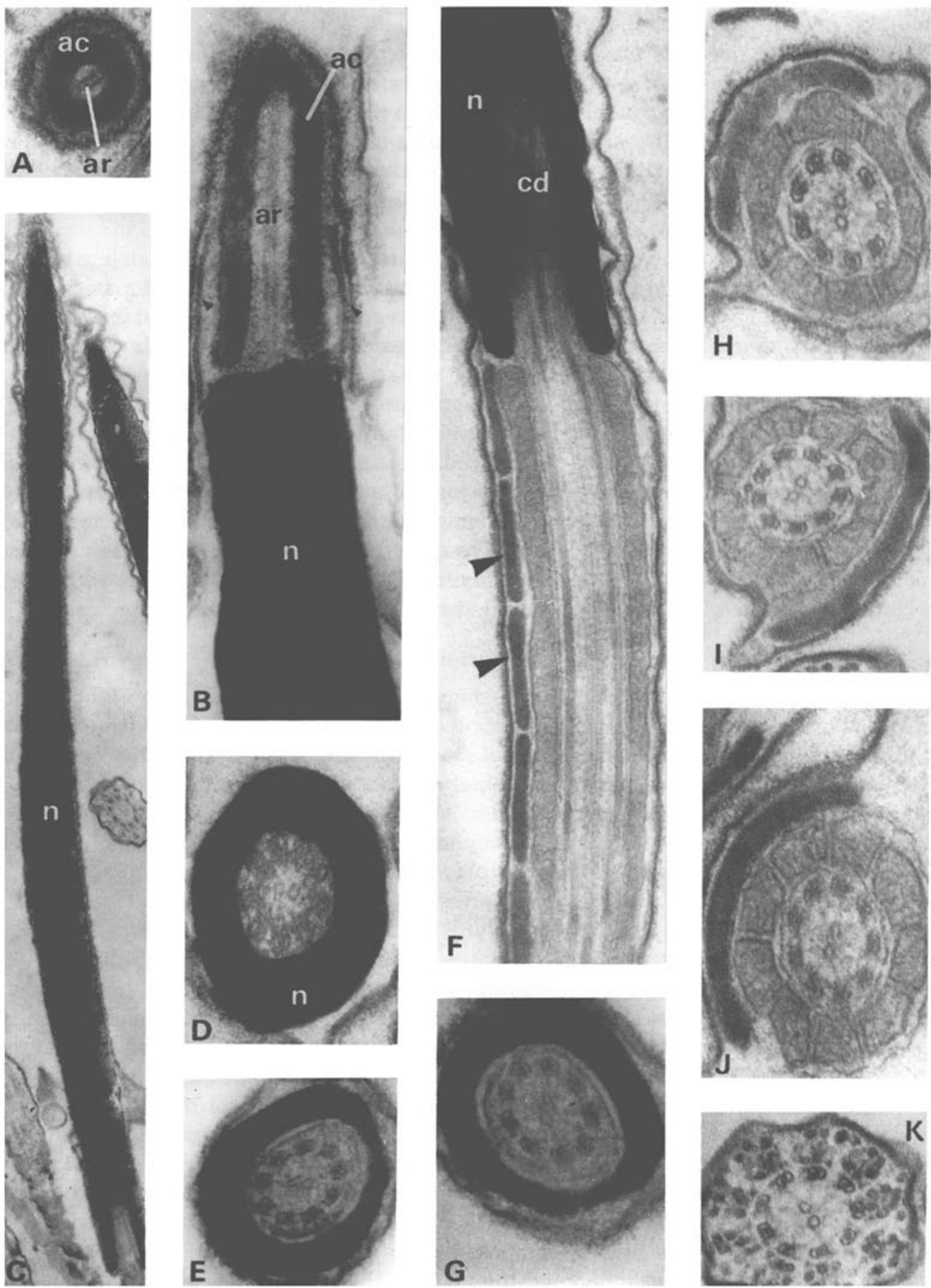
is membrane-bound and filled with a finely granular material, (2) is approximately 0.36 $\mu \mathrm{m}$ in length and between 0.036 and $0.04 \mu \mathrm{m}$ in thickness, and (3) contains no cristae, modified cristal surfaces or paracrystalline deposits, Preliminary observations on euspermatozoon development by the author have not, as yet, clarified the origin of the accessory midpiece sheath. Since the sheath lies outside the mitochondrial membrane (and contains no cristae or cristal derivative) it possibly is derived from ER or Golgi activity rather than mitochondrial metamorphosis. The dense blocks which comprise the head/body of cerithiacean, viviparacean and cyclophoracean paraspermatozoa bear some resemblance to the accessory midpiece sheath of Campanile euspermatozoa, and are known to be formed either within the endoplasmic reticular cisternae (see Yasuzumi \& Tanaka, 1958; Healy \& Jamieson, 1981) or by joint ER-Golgi participation (Selmi \& Giusti, 1980). It will be interesting to determine whether the accessory midpiece sheath of Campanile euspermatozoa is homologous with the mosaic sheath of paraspermatozoa.

\section{Glycogen picce}

Beyond the midpiece the axoneme is sheathed by nine tracts of electron-dense, glycogen granules (one tract associated with each doublet - see Fig. 1K). This pattern of granule arrangement occurs in euspermatozoa of most mesogastropods and neogastropods. A dense ring structure occurs at the junction of the midpiece and glycogen piece, but in all available longitudinal sections through this zone, the midpieceglycogen piece junction was recurved onto the nucleus (recurvature of euspermatozoa described below). There is no reason to believe that this unusual condition is characteristic of Campanile euspermatozoa. The morphology of Campanile euspermatozoa is summarized in Figure $4 \mathrm{a}-\mathrm{g}$.

\section{Recurvature of euspermatozoa}

A relatively large proportion of Campanile euspermatozoa observed under the electron microscope (possibly as many as 30-40\%) were found to be strongly curved always apparently within the confines of the plasma membrane. Figures $2 \mathrm{~A}-\mathrm{F}$ show various recurved euspermatozoa cut in longitudinal section (Figs 2A, $B, E$ ) or transverse section (Figs 2C,D,F). Since recurvature occurs within the midpiece region, both the terminal region of the midpiece and initial portion of the glycogen piece overlap with the nucleus (Figs 2A-D). As can be observed in Figure 2E, the microtubules of the axonemal complex are bent in an angular fashion at the point of recurvature. The dense

Fig. 1. Campanile symbolicum. A Transverse section through acrosomal cone above level of accessory membrane (x 63 730). B Longitudinal section through acrosome and apex of nucleus note accessory membrane (small arrow heads) (x 67470 ). C Longitudinal section through nucleus note shallow basal invagination ( $x$ 18 600). D, E Transverse section through 'centriolar derivative' $(D, x 76470)$ and through axoneme $(E, \times 67070)$ within basal invagination of nucleus. $F$ Longitudinal section through basal invagination of nucleus and proximal portion of midpiece - note segments of accessory midpiece sheath (large arrow heads) ( $x$ 46 550). $G$ Transverse section through basal invagination of nucleus showing $9+2$ axoneme $(x 78160)$. H-J Transverse sections of midpiece showing presence of 7 or 8 midpiece elements (cristae faintly visible in $J$ ) and accessory midpiece sheath $(\mathrm{H}, \mathrm{J}, \times 78160 ; \mathrm{I}, \mathrm{x} 63 \mathrm{730})$. K Transverse section through glycogen piece - note 9 tracts of granules associated with doublets of axoneme (x 69 500). ac - acrosomal cone; ar - axial rod material; cd - centriolar derivative; $\mathbf{n}$ - nucleus 

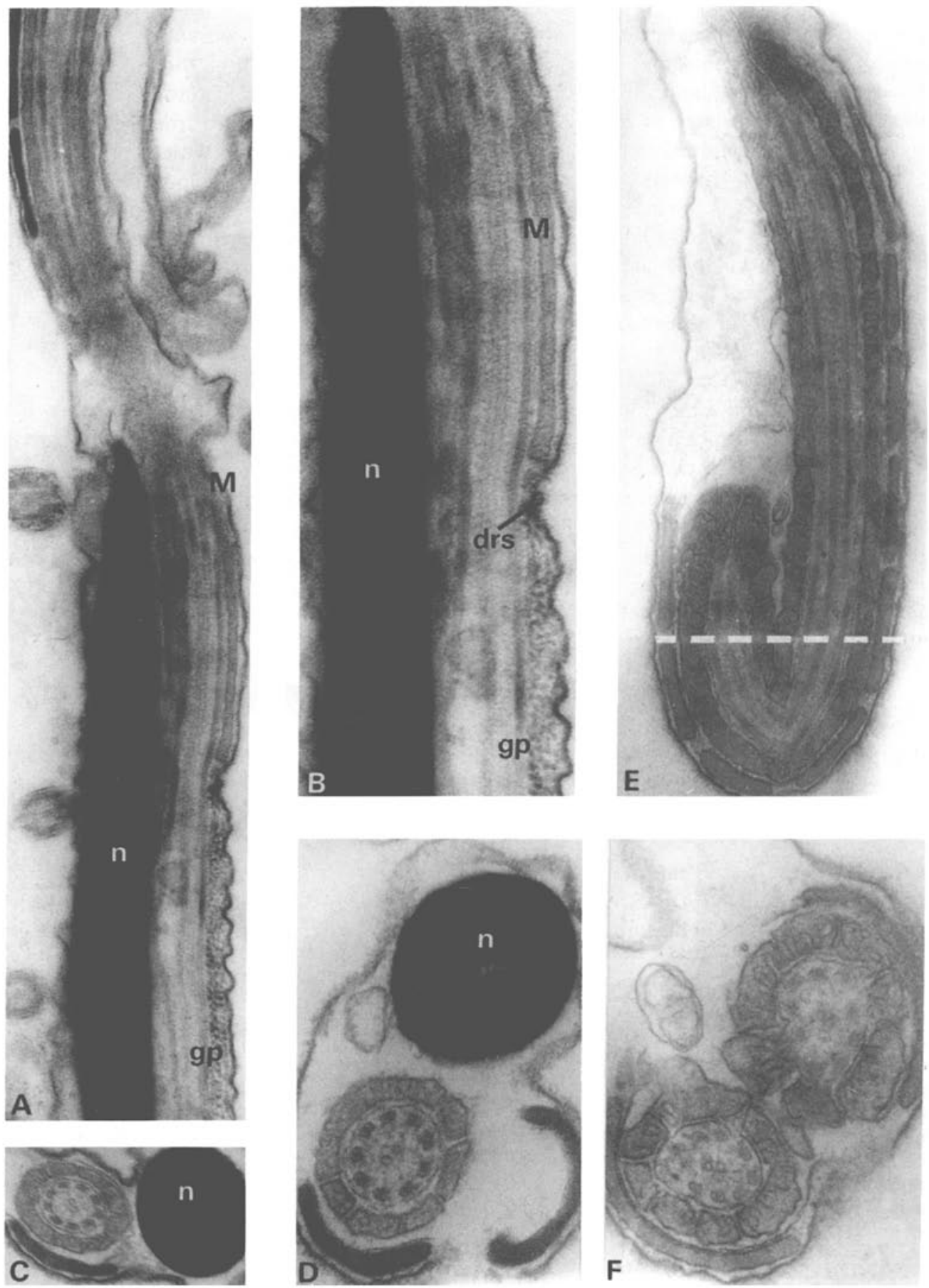
ring structure which occurs at the junction of midpiece and glycogen piece is fully formed in recurved euspermatozoa (see Fig. 2B). Rarely, duplicate segments of the accessory midpiece sheath may be present (see Fig. 2D). The electron-density of the segments of the accessory midpiece sheath varies markedly between euspermatozoa (compare Figs 2E,F with Figs 2A,C,D and Figs 1F,H-J), possibly reflecting differences in maturity (electron-density of sheath increasing with maturity). Although no paraspermatozoa of Campanile were found to be recurved or in any way malformed, it remains possible that the recurved euspermatozoa occurring in the sperm duct of this species, may be the end-product of abnormal development. A more likely explanation for this unusual phenomenon is that euspermatozoa of the specimen examined (a wintercollected specimen) were not mature. Recurvature of immature euspermatozoa is known to occur in at least some other cerithiaceans (Healy, 1984) and in viviparaceans (see Garton \& Byrd, 1977). This topic is treated in fuller detail in the discussion.

\section{Paraspermatozoa}

Two types of paraspermatozoa are produced by Campanile : (1) those possessing a nuclear core (nucleate paraspermatozoa) and (2) those which lack a nuclear core (anucleate paraspermatozoa). Both nucleate and anucleate paraspermatozoa are divisible into a head region followed by a tail tuft (two to three tails) - the commonest form of cerithiacean paraspermatozoa.

\section{Nucleate paraspermatozoa}

The bulk of the head of nucleate paraspermatozoa consists of a filiform, highly condensed nuclear core, enclosed by a mosaic sheath (composed of numerous, closefitting blocks). Axonemes evidently attach to the nuclear core near the base of the head (Fig. 3J), while apically, an acrosome-like structure is observed (Fig. 3H). Both the mosaic sheath and its enclosed nuclear core become gradually reduced in diameter toward the head apex (compare Figs $3 I$ and J inset). Approaching the base of the head, however, the mosaic sheath becomes semicylindrical in shape (only partly covering mitochondria, axonemes and nuclear core - see Fig. 3K). This arrangement continues even after termination of the nuclear core (see Fig. 3J). Such a configuration is reminiscent of the midpiece of Campanile euspermatozoa (see Figs 1,2 ) with the exception that the mosaic sheath is composed of numerous, often angularly-shaped blocks. The transverse section shown in Figure 3K clearly shows the multiple, dense blocks of the mosaic sheath - as distinct from the regularly-shaped segments of the accessory midpiece ( of

Fig. 2. Campanile symbolicum. A Longitudinal section through euspermatozoon showing midpiece-glycogen piece recurved onto nucleus - note that accessory midpiece sheath terminates before reaching midpiece-glycogen piece junction ( $x 22680$ ). B Detail of $2 \mathrm{~A}$ showing dense ring structure at junction of midpiece and glycogen piece (x 40 130). C Transverse section through recurved euspermatozoon ( $x 41800$ ). D Transverse section of euspermatozoon, with additional segment of accessory midpiece sheath (x 72 700). E Longitudinal section through point of recurvature in midpiece region - note sharp bending of axoneme, white broken line denotes level through which $2 F$ passes ( $x 40400$ ). F Transverse section through midpiece at level shown in $2 E-$ note the reduced electron-density of the accessory midpiece sheath in this figure and in $2 \mathrm{E}$ in comparison with 2C,D, possibly indicating immaturity of sheath in $2 E, F(x 65000)$. drs - dense ring structure; 

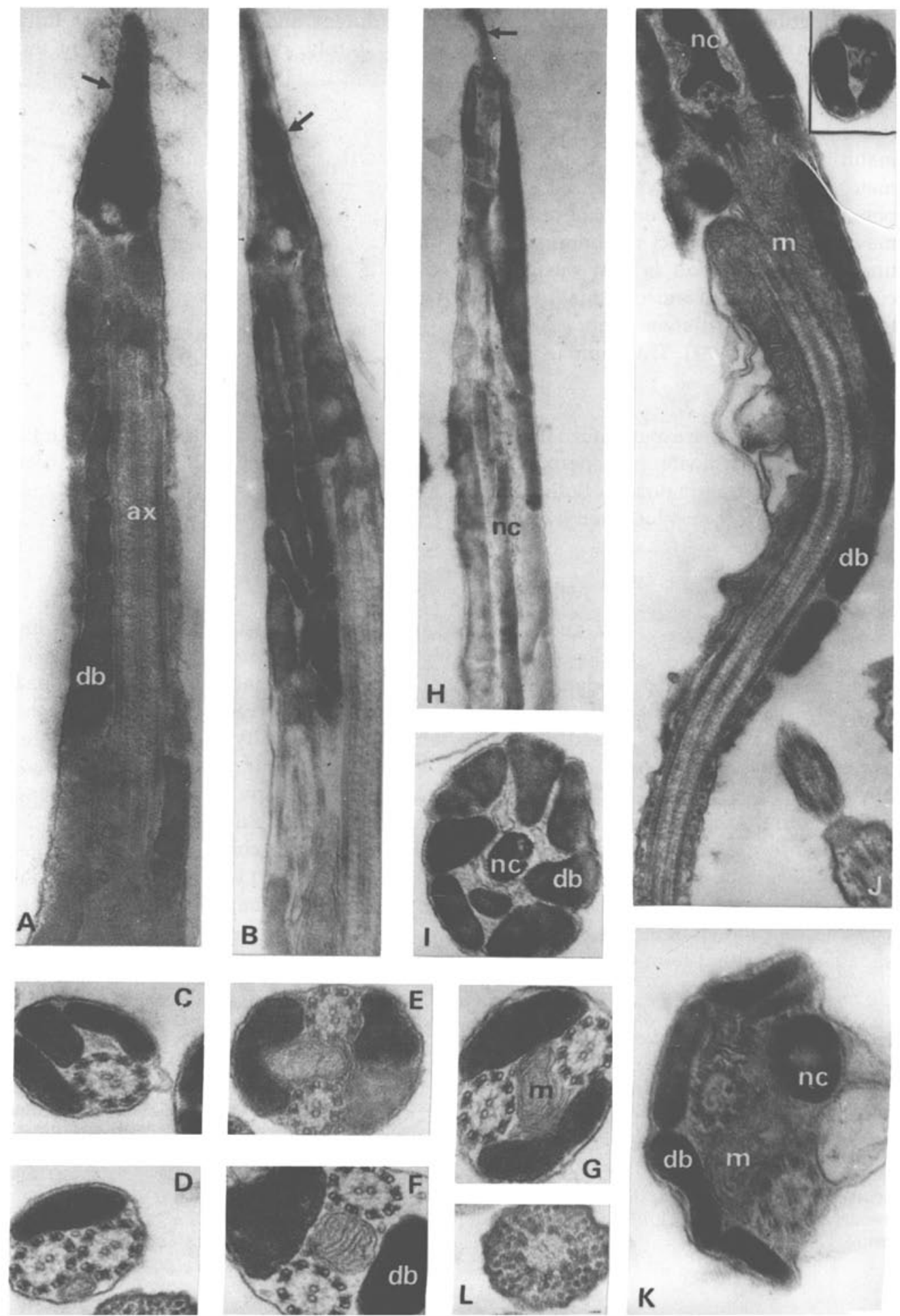

K 
euspermatozoa) which are whole and not subdivided in transverse section. Nevertheless, the possibility that the mosaic sheath (of paraspermatozoa) and the accessory midpiece sheath (of euspermatozoa) may be homologous structures remains to be determined. Complete overlap between the head and the mitochondrial region of the nucleate paraspermatozoon makes it impossible to recognize a true 'midpiece' (cf. Healy \& Jamieson, 1981; Healy, 1982b), Figure 3J shows only one of the two or three tails comprising the tail tuft. A dense ring structure and granular glycogen deposits are associated with each tail (see Fig. 3J,L). Phase-contrast light microscopy indicates a length of between 11.5 and $12 \mu \mathrm{m}$ for the head approximately $40 \mu \mathrm{m}$ for the tail tuft.

\section{Anucleate paraspermatozoa}

An acrosome-like structure also forms the apex of the anucleate paraspermatozoon head, but is well developed in comparison with that of the nucleate paraspermatozoon and is often basally invaginated (Figs $3 A, B$ ). The head and tail tuft are both proportionately much longer than the corresponding regions of nucleate paraspermatozoa (head of anucleate paraspermatozoa - 28-30 $\mu \mathrm{m}_{\text {i }}$ tail tuft 60-115 $\mu \mathrm{m}$ ). Elongate mitochondria (with unmodified cristae, as also observed in nucleate paraspermatozoa) and two axonemes - both only partly surrounded by the mosaic sheath - persist almost to the base of the acrosome-like structure (Figs 3A-D). Axonemal attachment takes place at slightly different levels near the head apex, (see Figs 3A-D) and appears to involve fusion of a short attachment complex (sensu Healy \& Jamieson, 1981) to a block or blocks of the mosaic sheath (Fig. 3B). It is interesting to observe that mitochondria essentially take the place of the nuclear core (of nucleate paraspermatozoa) as the axial component of the paraspermatozoon head (see Figs 3E-G).

The structure of Campanile paraspermatozoa (nucleate and anucleate) is summarized in Figure 4.

\section{DISCUSSION}

\section{Reproductive biology of Campanile symbolicum}

Using light microscopy, Houbrick (1981a) observed only 'eupyrene sperm' (euspermatozoa) in the sperm duct of Campanile symbolicum collected during May 1979 at Point Peron (Western Australia). Despite this finding, Houbrick was aware of the pronounced sperm dimorphism occurring in other cerithiaceans and went on to suggest

Fig. 3. Campanile symbolicum. A-G Anucleate paraspermatozoa: A, B Longitudinal sections through acrosome-like structure (arrows) - note dense blocks of mosaic sheath, and penetration of axonemes and mitochondria close to base of acrosome-like structure (x 45 550). C-G Series of transverse sections through anucleate paraspermatozoon head - note position of mitochondria between axonemes (x 47300$)$. $\mathrm{H}-\mathrm{K}$ Nucleate paraspermatozoa: H Longitudinal section through acrosome-like structure (arrow), mosaic sheath and nuclear core ( $x 31200$ ). I Transverse section through head showing nuclear core ( $x 44600$ ). J Longitudinal section through base of head and proximal region of tail tuft - note mitochondria, mosaic sheath, glycogen surrounding the only axoneme visible, dense ring structure ( $x 36$ 800), Inset: Transverse section near apex of head region (x 40140 compare with 3 I). K Transverse section through base of nucleate paraspermatozoon (x 53600 ). L Transverse section through tail region of either nucleate or anucleate paraspermatozoon showing periaxonemal glycogen (x 48 400). ax-axoneme; db - dense blocks of mosaic sheath; $m$ mitochondria; nc - nuclear core 
that the phenomenon 'should be looked for more closely in spring during the height of the reproductive season, when animals are seen pairing' (p. 278). The present work establishes the existence of both euspermatozod and paraspermatozoa (in approximately equal proportions) in Campanile collected during late June 1982 (mid-winter) at Point

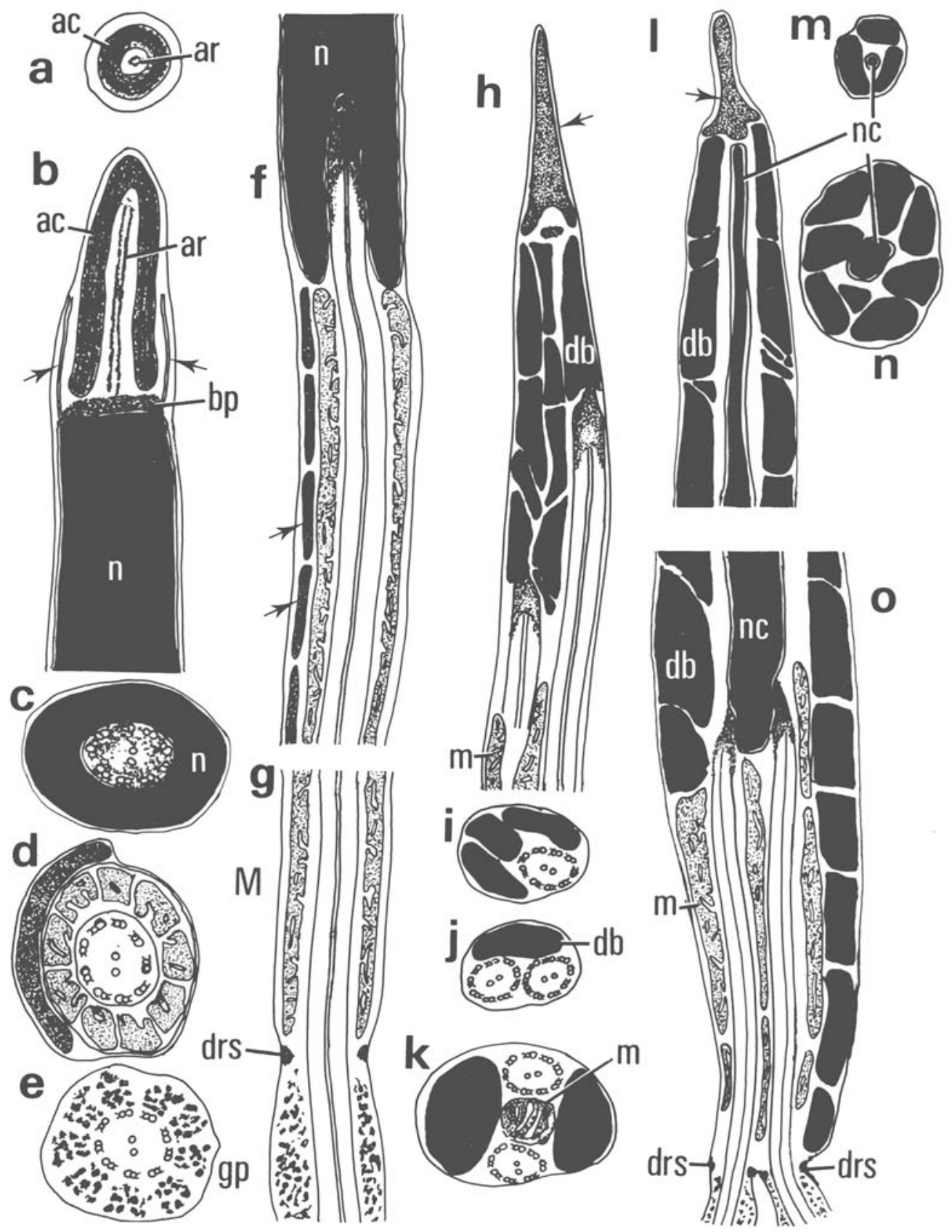


Peron - still well in advance of the spawning season which occurs from September to November ${ }^{*}$. The recurved shape of many euspermatozoa is possibly due to immaturity or abnormal development and was only observable under the electron microscope (perhaps because of the fact that the euspermatozoa were recurved within the plasma membrane). This structural pecularity is discussed in more detail in the following section of the discussion.

No information could be obtained to comment on Houbrick's (1981a) two interesting suggestions: (1) that $C$. symbolicum may be a protandric hermaphrodite (based on the occurrence of a seminal receptacle in both sexes [more developed in females] and shell size/sex correlation); or (2) that sperm transfer in this species may be effected by spermatophores (Houbrick reports the possible remains of a disintegrating spermatophore in the female oviducal groove). Spermatophores are known to occur in families such as the Cerithiidae (Houbrick, 1973, 1981c), Modulidae (Houbrick, 1980), Diastomatidae (Houbrick, 1981b), Pleuroceridae (Woodard, 1935; Dazo, 1965) and Potamididae (Houbrick, 1984c) and as suggested by Houbrick (1980), use of these structures may be the usual method of sperm transfer in the Cerithiacea. The aphallic condition of cerithiaceans adds further support to this view.

\section{Recurvature of euspermatozoa}

It has been shown in this study that many of the euspermatozod taken from the sperm duct of Campanile symbolicum are strongly recurved. The exact significance of this is at present very difficult to establish since paraspermatozoa of Campanile (both nucleate and anucleate) show no evidence of recurvature and the author is unaware of any published account of euspermatozoal recurvature in any other gastropod species. During euspermiogenesis in the freshwater neritacean Theodoxus fluviatilis, the

- Houbrick (1981a) citing personal communication with Dr. R. Black (University of Western Australia)

Fig. 4. Campanile symbolicum. Pictorial summary of euspermatozoa and paraspermatozoa. All figures except Figs $4 \mathrm{~g}, 40$, traced from actual micrographs. a-g E u s p e rm a to $\mathrm{zo}$ a : a Transverse section (T.S) of acrosome above level of accessory membrane ( $x$ 47 250). b Acrosome and apical region of nucleus; arrows indicate accessory membrane (x 50000), (c-e) T.S. through basal invagination of nucleus ( $\mathrm{c}$ - transition from axoneme to centriolar derivative, $\mathrm{x} 56500$ ), midpiece ( $\mathrm{d}$ - note accessory midpiece sheath, cristate midpiece elements, x 56500$)$, glycogen piece (e - x $50500)$. $f, g$ Base of nucleus and proximal region of midpiece ( $\mathrm{f}$ - note accessory midpiece sheath arrows, $x 35000$ ), junction of midpiece and glycogen piece (g - note absence of accessory midpiece sheath in this region, presence of dense ring structure, $x 35000)$. h-o Parasperm a toz oa: $\mathrm{h}-\mathrm{k}$ Anucleate paraspermatozoa: h Anterior region showing acrosome-like structure (arrow), deep penetration of head by axonemes and mitochondria ( $x 35000$ ). $i-k$ T.S. showing transition from anterior region of head (i) with one axoneme, to two axonemes (j, below level of Fig. 4i) to two axonemes accompanied by mitochondrion ( $k$, below level of Fig. 4j) (i-k, x 35000$)$. 1-0 Nucleate paraspermatozoa: 1 Anterior region showing acrosome-like structure (arrow), nuclear core surrounded by mosaic sheath ( $\mathrm{x} 40000)$. m,n T.S. through anterior and middle regions of head $(\mathrm{x}$ $33000)$. o Base of head overlapped completely with mitochondrial region, each tail exihibits granular glycogen deposits and is preceeded by a dense ring structure ( $x 25200$ ). ac - acrosomal cone; ar - axial rod material; bp - basal plate; $\mathrm{db}$ - dense blocks of mosaic sheath; drs - dense ring structure; gp-glycogen piece; $\mathrm{M}$ - midpiece; $\mathrm{m}$ - mitochondrion; $\mathrm{n}$ - nucleus; $\mathrm{nc}$ - nuclear core 
axoneme breaks into two sections - the posterior portion being reflected anteriorly and an angular, electron-dense body becoming associated with the resulting 'joint' in the euspermatozoan tail (see Giusti \& Selmi, 1982b). This is a specialized arrangement not known outside the Neritacea, and as such is not comparable with the simple bending of many Campanile euspermatozoa. Garton \& Byrd (1977) reported that immature, testicular 'eupyrene sperm' (euspermatozoa) and 'oligopyrene sperm' (paraspermatozoa) of Viviparus subpurpureus (Viviparacea, Vivipariidae) are morphologically distinguishable from mature sperm. In this species, the testicular euspermatozoa evidently exhibit a $180^{\circ}$ loop in the midpiece while testicular paraspermatozoa have a 'coiled head region' features not observed in mature sperm. The present author has observed the recurved shape of very late euspermatids (still associated with cytoplasm and microtubules) of the cerithiid Rhinoclavis vertagus (Healy, 1984) but not in euspermatozoa from the sperm duct (Healy, 1983a). It is conceivable that euspermatozoa extracted from the sperm duct of C. symbolicum collected during mid-winter (late June, 1982) may be recurved because of slight immaturity. As male individuals approach sexual maturity, the euspermatozoa contained within the sperm duct or packaged in spermatophores presumably straighten. Given that spawning occurs much later during the year (from September to November; cf. Houbrick, 1981a), this explanation seems plausible, but requires substantiation. Unlike euspermatids of Rhinoclavis vertagus, neither euspermatozoa nor paraspermatozoa of Campanile were ever seen surrounded by microtubules or residual cytoplasm. Certainly an examination of spermatophores of Campanile (assuming that they do in fact occur in this species) and also sperm recovered from the seminal receptacle of 'female' snails would prove extremely useful in resolving this issue. Another possible reason for the recurvature of Campanile euspermatozoa also needs to be considered: that this may be the endproduct of abnormal development. Only a single sperm-containing individual was available for study, but despite this limitation it is remarkable that no abnormalities could be detected in either of the two types of paraspermatozoa. The present author has observed recurvature of the midpiece of Bembicium auratum euspermatozoa in addition to other abnormalities of the axonemal complex (Healy, 1984) but such examples are rare and at least in Bembicium, are clearly the result of developmental abnormalities.

\section{Comparative sperm structure - Campanile euspermatozoa}

The true conical shape of the acrosomal cone of Campanile euspermatozoa occurs in most other mesogastropods (including some cerithiaceans), and neogastropods, the primitive spermatozoa of archaeogastropods, bivalves and scaphopods (for references see Popham, 1979; Franzén, 1983; Kohnert \& Storch, 1983; Healy, 1983a), and in fact many invertebrate groups (see Dan, 1970; Baccetti, 1979 for references). In contrast, the acrosomal cones of some cerithiaceans (cerithiids, some potamidids, Australaba; cf. Healy, 1983a), a few rissoaceans (Giusti, 1971; Kohnert, 1980; Healy, 1983b) and the cyclophoracean Liarea ornata (Healy, 1984) are flattened in form to varying degrees. Presumably this character state can be considered 'advanced' relative to the very widespread conically-shaped acrosomes of other prosobranchs, and perhaps is relatable to egg structure. As observed in other cerithiacean species, the acrosomal cone of Campanile euspermatozoa lacks the hollow, apically-positioned bleb (essentially an 
expanded portion of the acrosomal cone membrane, closely adherent to the plasma membrane) known to exist in acrosomes of many other mesogastropods and neogastropods (cf. Walker \& MacGregor, 1968; Giusti \& Mazzini, 1973; Huaquin \& BustosObregon, 1981; Koike \& Nishiwaki, 1980; also Healy, 1984). Despite this, euspermatozoa of Campanile do possess an accessory membrane attached to the basal plate of the acrosomal complex - a feature absent in euspermatozoa of other cerithiaceans but present in the acrosomes of many other mesogastropod and neogastropod species (Koike \& Nishiwaki, 1980; Healy, 1984). Whether this peculiar shared feature is of systematic importance, or merely independently acquired, can only be determined by continued comparative studies of cerithiacean sperm structure.

Nuclei of many mesogastropod and some neogastropod euspermatozoa, like those of Campanile are rod-shaped and short or at least moderately so, with a shallow basal invagination containing the 'centriolar derivative' (never a classic centriole) and the proximal portion of the axoneme (cf. Giusti, 1969; Bulnheim, 1962; Kohnert, 1980; Koike \& Nishiwaki, 1980; Healy 1982a,b, 1983a,b). A number of mesogastropods and many neogastropods have long euspermatozoon nuclei $(30-130 \mu \mathrm{m})$ which are almost totally invaginated (enclosing therefore, a substantial portion of the axoneme) and in some families such as the Littorinidae and Eulimidae, species with either style of nuclear morphology may be found (Healy, 1984). To date no cerithiacean species has been shown to possess euspermatozoa with deeply invaginated nuclei. The length of the nucleus of Campanile euspermatozoa $(9.5 \mu \mathrm{m})$ is exceptional in that it is three times the length of euspermatozoa nuclei of all other investigated cerithiacean species. In this aspect, the euspermatozoa of Campanile resemble those of some non-cerithiacean mesogastropod families such as the Epitoniidae (Bulnheim, 1962; Nishiwaki \& Tochimoto, 1969; Healy, 1984), Strombidae (Koike \& Nishiwaki, 1980) and the Naticidae (Healy, 1984).

It is principally the fine structure of the midpiece region which distinguishes euspermatozoa of Campanile from those of other gastropods - most notably those of other cerithiacean families. The midpiece elements of Campanile : (1) possess essentially unmodified cristae (lack the parallel cristal plates of other cerithiacean euspermatozoa), (2) are seven to eight in number (four in other cerithiaceans) and (3) are partially enclosed by an accessory midpiece sheath (no equivalent in any studied gastropod, cerithiacean or otherwise). Characters (1) and (2) are commonly encountered in euspermatozoa of non-cerithiacean mesogastropods and neogastropods, but it is important to note that the midpiece elements of Campanile euspermatozoa are nonhelically arranged around the axoneme as is observed in other cerithiaceans and also those cyclophoracean species that have been studied (Selmi \& Giusti, 1980; Healy, 1984).

With the exception of Stenothyra (see Healy, 1983b) the arrangement of granules in the glycogen piece of meso- and neogastropod euspermatozoa follows the pattern shown in this paper for Campanile - that is, nine continuous tracts, one associated with each axonemal doublet (references this paper). This pattern is distinct from the simple packing of granules around the axoneme observed in spermatozoa of pulmonate and opisthobranch species which actually possess a glycogen piece (the storage of substantial glycogen deposits within the mitochondrial derivative of euthyneuran spermatozoa has evidently made redundant the necessity for a glycogen piece, hence its reduction or absence in many species; see Healy \& Willan, 1984 for references). 


\section{Comparative sperm structure - Campanile paraspermatozoa}

Paraspermatozoa of most cerithiaceans are divisible into a 'head' and a tail tuft, with a 'midpiece' (axonemes surrounded by mitochondria) recognizable in some groups (see Melone et al., 1980; Healy \& Jamieson, 1981; Healy, 1982b). Comparison of cerithiacean paraspermatozoa with those of other prosobranchs, especially those of the Viviparacea (which probably approach most closely the form of cerithiacean paraspermatozoa) has been given in other papers (Healy \& Jamieson, 1981; Healy, 1982b) but for the purposes of this discussion some recapitulation of this work is necessary. Paraspermatozoa of the cerithiacean families Cerithiidae, Turritellidae, Potamididae and Australaba possess a head composed of a nuclear core (a string-shaped condensed remnant of the paraspermatid nucleus to which the axonemes often become attached), surrounded by a mosaic sheath of block-shaped bodies. An acrosome-like structure normally occupies the head apex while posteriorly, mitochondria and the axonemes of the tail tuft may (occasionally) penetrate quite deeply into the head. In paraspermatozoa of Obtortio (family uncertain) a nuclear core is absent and the multiple axonemes attach to a rod-shaped structure (possibly of nuclear origin) at the head apex. The present study has revealed two types of paraspermatozoa in Campanile - one of which possesses a nuclear core (with axonemes attaching to the base of the head) and the other type lacking any apparent nuclear remnant (axonemes penetrating almost to the base of the acrosome-like structure, and evidently attaching to the blocks of the mosaic sheath). Although paraspermatozoal dimorphism has not been demonstrated in any other cerithiaceans, it is well known in viviparacean species (Yasuzumi \& Tanaka, 1958; Nishiwaki, 1964; Tochimoto, 1967) and in certain other mesogastropod groups such as the Tonnacea and Epitoniacea (Nishiwaki, 1964; Tochimoto, 1967; Nishiwaki \& Tochimoto, 1969; Buckland-Nicks et al., 1982). On balance, however, the paraspermatozoa of Campanile resemble those of families such as the Cerithiidae, Potamididae and also, apparently, Turritellidae (mosaic sheath of head, nuclear core [nucleate paraspermatozoa only], acrosome-like structure, tail tuft).

\section{Systematic importance of cerithiacean euspermatozoa - an update}

Previous investigations have shown that the midpiece region of cerithiacean euspermatozoa consists of an axoneme surrounded by four, straight, midpiece elements each containing parallel cristal plates (Healy, 1982a, b, 1983a; Afzelius \& Dallai, 1983). Healy (1983a) grouped various cerithiacean families according to the shape of the midpiece elements and the acrosome. Owing to some recent confusion concerning the content of these groupings they are here restated and the basis for group division briefly summarized.

Group I (midpiece with two large and two small midpiece elements) - subgroup I(i): Cerithiidae, Turritellidae, Australaba (? family); subgroup I(ii): Planaxidae, Potamididae (subfamily Batillariinae only); Group II (midpiece with four equal-sized midpiece elements): Modulidae, Potamididae (subfamily Potamidinae only), Obtortio (? family position) ? Pleuroceridae.

The principal differences between subgroups I(i) and I(ii) lie in the relative size of the two small midpiece elements (extremely reduced in I[i], much less so in I[ii]) and also in the form of the acrosomal cone (compressed in I[i], truly conical in I[ii] - no data being 
available to Healy [1983a] for acrosome structure in the Turritellidae). Recently, the author has examined sea water-formalin fixed testis tissues of Siliquaria ponderosa (Siliquariidae), and although very poorly preserved, the midpiece of euspermatozoa appears to follow the pattern observed in subgroup I(i). This is consistent with Morton's (1955) conclusion (based on gross anatomy) that the Siliquariidae and Turritellidae are closely allied. In a very detailed account, Afzelius \& Dallai (1983) have investigated the occurrence of paired euspermatozoa in Turritella communis (Turritellidae; cf. Franzén, 1955 for light microscopic observations of spermiogenesis of paired euspermatozoa in this species). This work also reveal that the acrosomal cone of Turritella communis is, like the members of subgroup I(ii), truly conical in shape and not compressed like other members of subgroup I(i). In addition, Afzelius \& Dallai reported variation in the number and size of the midpiece elements in 'one or two percent' of all Turritella midpieces observed by them. The present author has also observed some variation of midpiece element number in euspermatozoa of some cerithiacean species (three to five midpiece elements in the potamidid Terebralia palustris) and occasionally duplication of the axoneme (Planaxis sulcatus), but such instances are rare (probably abnormalities) and do not in any way detract from the systematic importance of the midpiece region of cerithiacean euspermatozoa. It should be pointed out that the midpiece elements of the Turritella euspermatozoon shown in Figure 18 of Afzelius \& Dallai (1983) are clearly of different sizes (two large, two small - the small elements similar in size to subgroup I(ii) and not as stated by those authors as equally large (p. 317). The fact that euspermatozoa of Turritella communis (subgroup I[i]) show the same acrosomal features and - albeit rarely - the same midpiece form as euspermatozoa of subgroup I (ii) further strengthens ties between the two subgroups. In contrast, the differences in midpiece structure between the two subfamilies of the Potamididae (Batillariinae, Potamidinae; see Healy, 1983a) appear to be of great systematic importance. Midpiece structure in cerithiacean euspermatozoa (and in fact the spermatozoa of other internally fertilizing gastropods) is a distinctive and conservative character worthy of high taxonomic weighting. To date, the Potamididae is the only cerithiacean family known to show both Group I and Group II midpiece morphology.

\section{Systematic importance of Campanile spermatozoa}

Although Houbrick (1981a) has concluded that Campanile symbolicum is indisputably referable to the superfamily Cerithiacea, his detection of a number of important and typically non-cerithiacean anatomical features in this species (including the albumen gland, buccal pouches, egg capsules linked by chalazae, small bipectinate osphradium, seminal receptacle in both sexes) leaves much doubt as to the precise relationship of the Campanilidae to other cerithiacean families. This problem is, unfortunately, exacerbated by the peculiar, possibly unique form of the euspermatozoon midpiece in Campanile (differences from other cerithiaceans outlined in previous section of discussion) and the fact that this species produces two types of paraspermatozoa (the first recorded example of paraspermatozoal dimorphism in the Cerithiacea). It should, however be emphasized that paraspermatozoa of Campanile share a number of important features with those of the Cerithiidae, Potamididae and evidently also the Turritellidae and Planaxidae (presence of a nuclear core [nucleate 
paraspermatozoa only], mosaic sheath, acrosome-like structure, head/tail tuft, body form). In many respects the anatomy and sperm morphology of Campanile helps to bridge ilie gap which exists between the Cerithiacea and the remainder of the Caenogastropoda' (other mesogastropods and the Neogastropoda). Further work on unstudied groups (including relict families such as the Diastomatidae) and more exhaustive analyses of sperm diversity in the large multigeneric families (Turritellidae [Orectospirinae], Cerithiidae [Plesiotrochus, Gourmya]) hopefully will permit a better understanding of the position of the Campanilidae within the Cerithiacea.

In summary, spermatozoal and anatomical characteristics of Campanile suggest: (1) that the Campanilidae should certainly be maintained as a distinct cerithiacean family (and not reduced to a subfamily or genus of the Cerithiidae; cf. Thiele, 1931; Ludbrook, 1971) and (2) that this family should, at least for the present time, occupy an isolated position within the Cerithiacea with remote links to the Cerithiidae, Potamididae and Turritellidae.

It is hypothesized that the Campanilidae probably diverged at an early stage from the primitive cerithiacean stock in which sperm dimorphism was established. Subsequently the family has remained a distinctive - though from an evolutionary standpoint relatively unimportant - branch of the Cerithiacea.

Acknowledgements. The author wishes to extend thanks to Dr. B. Jamieson and Dr. R. Willan for their reading and critical appraisal of the manuscript. Very special thanks are due to Dr. F. Wells (Curator of Molluscs, Western Australian Museum) for providing live Campanile symbolicum on three occasions. Without this live-collected material the present work would have been impossible, and it is therefore a pleasure to acknowledge Dr. Wells' generous assistance. The author also thanks staff members of the University of Queensland Electron Microscope Centre for their combined technical help. The work contained in this paper originally formed part of a $\mathrm{Ph}$. D. thesis (University of Queensland, supervisor: Dr. B. G. M. Jamieson) and was carried out with support from annual University Commission Grants and a Commonwealth Postgraduate Award.

\section{LITERATURE CITED}

Afzelius, B. A. \& Dallai, R., 1983. The paired spermatozoa of the marine snail, Turritella communis Lamarck (Mollusca, Mesogastropoda). - J. Ultrastruct. Res. 85, 311-319.

Baccetti. B., 1979. The evolution of the acrosomal complex. In: Comparative spermatology. Ed. by D. W. Fawcett \& J. M. Bedford. Urban \& Schwarzenberg, Baltimore, 305-328.

Buckland-Nicks, J. A., Williams, D., Chia, F. S. \& Fontaine, A, 1982. Studies on the polymorphic spermatozoa of a marine snail. I, Genesis of the apyrene sperm. - Biol. Cell. 44, 305-314.

Bulnheim, H.-P., 1962. Elektronenmikroskopische Untersuchungen zur Feinstruktur der atypischen und typischen Spermatozoen von Opalia crenimarginata (Gastropoda, Prosobranchia). - Z. Zellforsch, mikrosk. Anat. 56, 371-386.

Dan, J, C., 1970. Morphometric aspects of acrosome formation and reaction. In: Advances in morphogenesis. Ed. by M. Abercrombie, J. Brachet \& T. J. King. Acad. Press, New York, 8, 1-39.

Dazo, B. C., 1965. The morphology and natural history of Pleurocera acuta and Goniobasis Iivescens (Gastropoda: Cerithiacea : Pleuroceridae). - Malacologia 3, 1-80.

Franzén, $\AA$., 1955. Comparative morphological investigations into the spermiogenesis among Mollusca. - Zool, Bidr. Uppsala 30, 399-456.

Franzén, $\AA$., 1983. Ultrastructural studies of spermatozoa in three bivalve species with notes on evolution of elongated sperm nucleus in primitive spermatozoa. - Gamete Res. 7, 199-214.

Garton, D. \& Byrd, W., 1977. Spermiogenesis and activation of dimorphic sperm of the prosobranch gastropod Viviparus subpurpureus. - Am. Zool. 17, 945. 
Giusti, F., 1969. The spermatozoon of a fresh-water prosobranch mollusc. - J. submicrosc. Cytol. 1, 263-273.

Giusti, F., 1971. L'ultrastruttura dello spermatozoo nella filogenesi e nella sistematica dei molluschi gasteropodi. - Atti Soc, ital. Sci. nat. 112, 381-402.

Giusti, F. \& Mazzini, M., 1973. The spermatozoon of Truncatella (s. str.) subcylindrica (L.) (Gastropoda, Prosobranchia). - Monitore zool, ital. 7, 181-201.

Giusti, F. \& Selmi, M. G., 1982a. The atypical sperm in the prosobranch molluscs. - Malacologia 22, 171-181.

Giusti, F. \& Selmi, M. G., 1982b. The morphological peculiarities of the typical spermatozoa of Theodoxus fluviatilis (L.) (Neritoidea) and their implications for motility. -- J. Ultrastruct. Res. 78, $166-177$.

Healy, J. M., 1982a. An ultrastructural examination of developing and mature euspermatozoa in Pyrazus ebeninus (Mollusca, Gastropoda, Potamididae). - Zoomorphology 100, 157-175.

Healy, J. M., 1982b. Ultrastructure of paraspermatozoa, euspermatozoa and eusperm-like spermatozoa of Obtortio cf. fulva (Prosobranchia: Cerithiacea). - Helgoländer Meeresunters. 35 , $489-500$.

Healy, J. M., 1983a. Ultrastructure of euspermatozoa of cerithiacean gastropods (Prosobranchia: Mesogastropoda). - J. Morph. 178, 57-75.

Healy, J. M., 1983b. Ultrastructure of euspermiogenesis in the mesogastropod Stenothyra sp. (Prosobranchia, Rissoacea, Stenothyridae). - Zool. Scr. 12, 203-214.

Healy, J. M., 1984. The ultrastructure of gastropod spermatozoa and spermiogenesis. Thesis, Univ. Queensland (Brisbane), $370 \mathrm{pp}$.

Healy, J. M. \& Jamieson, B. G. M., 1981. An ultrastructural examination of developing and mature paraspermatozoa in Pyrazus ebeninus (Mollusca, Gastropoda, Potamididae). - Zoomorphology $98,101-119$.

Healy, J. M. \& Willan, R. C., 1984. Ultrastructure and phylogenetic significance of notaspidean spermatozoa (Mollusca, Gastropoda, Opisthobranchia) - Zool. Scr. 13, 107-120.

Houbrick, R. S., 1973. Studies on the reproductive biology of the genus Cerithium (Gastropoda: Prosobranchia) in the western Atlantic. - Bull. mar. Sci. 23, 875-904.

Houbrick, R. S., 1980. Observations on the anatomy and life history of Modulus modulus (Prosobranchia: Modulidae). - Malacologia 20,117-142.

Houbrick, R. S., 1981a. Anatomy, biology and systematics of Campanile symbolicum with reference to adaptive radiation of the Cerithiacea (Gastropoda: Prosobranchia). - Malacologia 21, $263-289$.

Houbrick, R. S., 1981b. Anatomy of Diastoma melanioides (Reeve, 1849) with remarks on the systematic position of the family Diastomatidae (Prosobranchia: Gastropoda). - Proc. biol. Soc. Wash. $94,598-621$.

Houbrick, R. S., 1981c. Anatomy and systematics of Gourmya gourmyi (Prosobranchia: Cerithiidae), a Tethyan relict from the southwest Pacific. - Nautilus 95, 2-11.

Houbrick, R. S., 1984a. The giant creeper, Campanile symbolicum Iredale, an Australian relict marine snail. In: Living fossils. Ed. by N. Eldredge \& S. M. Stanley. Springer, New York, $232-235$.

Houbrick, R. S., 1984b. Diastoma melanioides (Reeve), a relict snail from, Australia. In: Living fossils. Ed. by N. Eldredge \& S. M. Stanley. Springer, New York, 236-239.

Houbrick, R. S., 1984c. Revision of higher taxa in genus Cerithidea (Mesogastropoda: Potamididae) based on comparative morphology and biological data. - Am. malacol. Bull. 2, 1-20.

Huaquin, L. G. \& Bustos-Obregon, E., 1981. Ultrastructural analysis of spermatid differentiation in Concholepas concholepas. - Archs Biol., Bruxelles 92, 259-274.

Kohnert, R., 1980. Zum Spermiendimorphismus der Prosobranchier, Spermiogenese und ultrastruktureller Aufbau der Spermien von Bithynia tentaculata (L.). - Zool. Anz. 205, 145-161.

Kohnert, R. \& Storch, V., 1983. Ultrastrukturelle Untersuchungen zur Morphologie und Genese der Spermien von Archaeogastropoda. - Helgoländer Meeresunters. 36, 77-84.

Koike, K. \& Nishiwaki, S., 1980. The ultrastructure of dimorphic spermatozoa in two species of the Strombidae (Gastropoda: Prosobranchia). - Venus, Kyoto 38, 259-274.

Ludbrook, N., 1971. Large gastropods of the families Diastomatidae and Cerithiidae (Mollusca: Gastropoda) in southern Australia. - Trans. R. Soc. S. Aust. 95, $29-42$. 
Melone, G., Lora Lamia Donin, C. \& Cotelli, F, 1980. The paraspermatic cell (atypical spermatozoon) of Prosobranchia: a comparative ultrastructural study. - Acta zool. Stockh. 61, 191-201.

Morton, J. E, 1955. The evolution of vermetid gastropods. - Pacif. Sci. 9, 3-15.

Nishiwaki, S., 1964. Phylogenetical study on the type of the dimorphic spermatozoa in Prosobranchia. - Scient. Rep. Tokyo Kyoiku Daig. (B) 2, 237-275.

Nishiwaki, S. \& Tochimoto, T., 1969. Dimorphism in typical and atypical spermatozoa forming two types of spermatozeugmata in two epitoniid prosobranchs. - Venus, Kyoto 38, 37-49.

Popham, J. D., 1979. Comparative spermatozoon morphology and bivalve phylogeny. - Malacol. Rev. $12,1-20$.

Selmi, M. G. \& Giusti, F, 1980. Structure and function in typical and atypical spermatozoa of Prosobranchia (Mollusca). I. Cochlostoma montanum (Issel) Mesogastropoda. (1). - Atti Accad. Fisiocr. Siena 1980, 115-147.

Thiele, J., 1931. Handbuch der systematischen Weichtierkunde. Fischer, Jena, 1, 1-376.

Tochimoto, T., 1967. Comparative histochemical study of the dimorphic spermatozoa of the Prosobranchia with special reference to polysaccharides. - Scient. Rep. Tokyo Kyoiku Daig. (B). 13, 75-109.

Walker, M. \& MacGregor, H. C., 1968. Spermatogenesis and the structure of the mature sperm in Nucella lapillus (L.). - J. Cell Sci. 3, 95-104.

Woodard, T, M., (Jr.) 1935. Spermic dimorphism in Goniobasis laqueata (Say). - J. Morph. 57, 1-23.

Yasuzumi, G. \& Tanaka, H., 1958. Spermatogenesis in animals as revealed by electron microscopy. VI. Researches on the spermatozoon-dimorphism in a pond snail Cipangopaludina malleata. $-\mathrm{J}$. biophys, biochem. Cytol. 4, 621-632. 